\title{
IMPLEMENTASI FILTER INFINITE IMPULSE RESPONSE (IIR) DENGAN RESPON ELLIPTIC DAN BESSEL MENGGUNAKAN DSK TMS320C6713
}

\section{IMPLEMENTATION OF INFINTE IMPULSE RESPONSE (IIR) FILTER WITH BESSEL AND ELLIPTIC RESPONSE USING DSK TMS320C6713}

\author{
Lita Lidyawati ${ }^{1}$, Arsyad Ramadhan Darlis ${ }^{2}$, Satria Ilma Romadoni ${ }^{3}$ \\ 1,2,3 Jurusan Teknik Elektro Institut Teknologi Nasional (ITENAS) Bandung \\ 1lita.sunoko@gmail.com, ${ }^{2}$ arsyaddarlis@gmail.com, ${ }^{3}$ satria.ilma.romadoni@gmail.com
}

\begin{abstract}
Abstrak
Dalam teknologi masa kini, sebuah sistem terbentuk dari beberapa subsistem. Salah satu bagian subsistem yang sangat penting adalah filter. Filter didefinisikan sebagai proses atau rangkaian yang melewatkan pita frekuensi tertentu yang diinginkan dan meredam pita frekuensi lainnya. Dalam penelitian ini digunakan jenis respon frekuensi Elliptic dan Bessel. Simulasi dilakukan dengan menggunakan software Matlab dengan memasukan frekuensi passband, frekuensi stopband, ripple passband, dan stopband attenuation yang telah dirancang. Dengan frekuensi sampling sebesar $15000 \mathrm{~Hz}$, frekuensi passband sebesar $3000 \mathrm{~Hz}$, frekuensi stopband sebesar 3500 $\mathrm{Hz}$ untuk Elliptic dan $5000 \mathrm{~Hz}$ untuk Bessel. Setelah simulasi dilakukan implementasi filter dengan parameter yang sama menggunakan DSK TMS320C6713 dengan bantuan software CCS. Parameter pengujian dari implementasi filter adalah respon magnitude, frekuensi cut-off, bandwidth, dan faktor kualitas dengan hasil simulasi yanng tidak menunjukan perbedaan yang signifikan. Memory yang digunakan pada DSK TMS320C6713 sebesar 2782 Bytes dari 16 MB.
\end{abstract}

Kata kunci: filter digital, Infinite filter response, elliptic, bessel, respon magnitude, frekuensi cut-off, DSK TMS320C6713

\begin{abstract}
In today's technology, system is made from several subsystems. One part that very important subsystem is filter. Filter is defined as a process or series that skip certain desired frequency band and other frequency bands drown. This study used the type of Elliptic and Bessel frequency response. Simulations performed using Matlab software by entering a frequency passband, stopband frequency, passband ripple, and stopband attenuation that has been designed. With a sampling frequency of $15000 \mathrm{~Hz}$, a frequency of $3000 \mathrm{~Hz}$ passband, stopband frequency of 3500 $\mathrm{Hz}$ to $5000 \mathrm{~Hz}$ for Elliptic and Bessel. After the simulation is done implementation of the filter with the same parameters using TMS320C6713 DSK with the help of software CCS. Parameter testing of the implementation of the filter is the magnitude response, the cut-off frequency, bandwidth and quality factor with yanng simulation results showed no significant difference. Memory used on TMS320C6713 DSK of 2782 Bytes of 16 MB.
\end{abstract}

Keywords: digital filter, infinite filter response, elliptical, bessel, magnitude response, cut-off frequency, DSK TMS320C6713 


\section{PENDAHULUAN}

Filter adalah rangkaian yang berfungsi untuk melewatkan dan menahan sinyal pada frekuensi tertentu. Filter ini dapat melewatkan dan menahan sinyal pada frekuensi yang diinginkan sesuai dengan perhitungan yang telah dilakukan. Dalam aplikasinya, filter dibutuhkan adalah filter yang memiliki karakteristik dengan bentuk ideal. Namun sampai saat ini belum ada yang dapat membuat filter dengan bentuk yang benar-benar ideal. Oleh karena itu dilakukan proses mendapatkan fungsi transfer filter yang memenuhi spesifikasi filter yang dibutuhkan.

Penelelitian ini mengacu kepada Penelitian sebelumnya mengenai implementasi filter IIR yang dilakukan oleh Muhamad Aswan [1] yang berjudul "Pewujudan Tapis Digital Bandpass IIR Menggunakan DSK TMS320C6713" Merancang Filter Digital dengan Respon Elliptic dengan bantuan Matlab FDATool (Filter Design and Analysis Tool). Implementasi dilakukan ke DSK TMS320C6713TM dengan filter yang telah dirancang di Simulink. Hasil pengujian menunjukan bahwa tanggapan magnitude sesuai dengan rancangan untuk spesifikasi filter 1-2 kHz.

Penelitian lainnya yang juga berkaitan dilakukan oleh Erwin Gidion [2] yang berjudul "Pewujudan Tapis digital FIR Pemilih Frekuensi Menggunakan DSK TMS320C6713" Implementasi tapis digital FIR pemilih frekuensi Low Pass Filter (LPF), High Pass Filter (HPF), Band Pass Filter (BPF), dan Band Stop Filter (BSF) menggunakan DSK (Digital Signal Processor Starter Kit) TMS320C6713.

Penelitian lainnya juga yang dijadikan acuan dilakukan oleh Solihin Suparman [5] yang berjudul "Simulasi Perancangan Filter Analog dengan Repon Chebyshev menggunakan MATLAB versi 7.9" merancang simulasi filter dengan respon Chebyshev pada Low Pass Filter (LPF), High Pass Filter (HPF), Band Pass Filter (BPF), dan Band Stop Filter (BSF), kemudian menentukan bersarnya nilai kapastansi (C) dan induktansi (L) untuk berbagai orde dengan menggunakan Electronic Workbench (EWB).

Selanjutnya penelitian yang juga dilakukan oleh Alfin Fernando Tamba [6] yang berjudul "Implementasi Filter Infinite Impulse Response (IIR) Dengan Respon Butterworth dan Chebyshev menggunakan DSK TMS320C6713" Perancangan filter IIR dengan melakukan perbandingan simulasi MATLAB dengan Implementasi DSK TMS320C6713 dengan repon frekuensi Butterworth dan Chebyshev. Berdasarkan hasil penelitian diatas maka dilakukan simulasi, perancangan, dan implementasi filter IIR dengan respon Elliptic dan Bessel menggunakan MATLAB dan DSP starter kit yaitu DSK TMS320C6713.

\section{METODOLOGI}

\subsection{Perancangan Filter IIR}

Untuk perancangan filter dilakukan penentuan spesifikasi dan perhitungan filter. Dilakukan perhitungan dahulu karena untuk mendapatkan orde filter yang akan diimplementasikan. Dalam perancangan filter IIR Elliptic dan Bessel digunakan frekuensi passband (Fp) sebesar $3000 \mathrm{~Hz}$, namun untuk frekuensi stopband (Fs) pada Elliptic dan Bessel berbeda karena sesuai dengan karakteristik dari kedua filter tersebut, untuk filter Elliptic Fs sebesar $3500 \mathrm{~Hz}$ dan filter Bessel Fs sebesar $5000 \mathrm{~Hz}$. frekuensi sampling $15000 \mathrm{~Hz}$, ripple passband sebesar $2 \mathrm{~dB}$ dan ripple stopband sebesar $40 \mathrm{~dB}$ untuk filter Elliptic. Parameter ini akan digunakan untuk filter LPF, HPF, BSF dan BPF respon frekuensi Elliptic dan Bessel.

a. Perhitungan Orde Filter

$k=\frac{\omega_{p}}{\omega_{s}}=0,8571$ 


$$
\begin{aligned}
& u=\frac{1-\sqrt[4]{1-k^{2}}}{2\left(1+\sqrt[4]{1-k^{2}}\right)}=0,0822 \\
& q=u+2 \cdot u^{2}+15 \cdot u^{9}+150 \cdot u^{13}=0,0957 \\
& D=\frac{10^{A_{S} / 10-1}}{10^{A_{p}} / 10-1}=1,7095 \times 10^{4} \\
& n=\left\lceil\frac{\log 16 \cdot D}{\log 1 / q}\right\rceil=5.3348 \approx 6 \\
& A_{S}=\text { Redaman Stopband } \quad D=\text { discrimination factor } \\
& k=\text { selectivity factor } \quad n=\text { orde filter } \\
& q=\text { modular constant }
\end{aligned}
$$

\subsection{Perancangan Simulasi dengan MATLAB}

Simulasi filter IIR dilakukan dengan dua tahap, yaitu simulasi menggunakan MATLAB $m$-file kemudian dilanjutkan dengan simulasi MATLAB Simulink.

\subsubsection{Simulasi Menggunakan MATLAB $m$-file}

Perancangan simulasi filter IIR dengan penulisan m-file bertujuan untuk mendapatkan koefisien filter $\mathrm{b}$ dan a (koefisien pembilang dan penyebut fungsi alih filter). Dalam simulasi ini kita dapat melihat hasil dari perancangan sistem filter. Hasil simulasi ini merupakan hasil yang mendekati ideal dari filter karena persamaan-persamaan yang digunakan pada script ini mengacu pada teori filternya. Langkah-langkah pemodelan simulasi menggunakan $m$-file secara singkat ditunjukan oleh diagram alir pada Gambar 3.

\subsubsection{Simulasi Menggunakan MATLAB Simulink}

Setelah program $\mathrm{m}$-file yang dibuat selesai, maka selanjutnya dilakukan simulasi dengan menggunakan simulink. Dibutuhkan simulasi menggunakan Simulink karena nantinya akan dilakukan pemodelan sistem filter menggunakan blok pada Simulink. Gambar 1 merupakan blok rangkaian simulasi MATLAB Simulink. Langkah-langkah pemodelan simulasi menggunakan simulink ditunjukan oleh diagram alir pada Gambar 3.

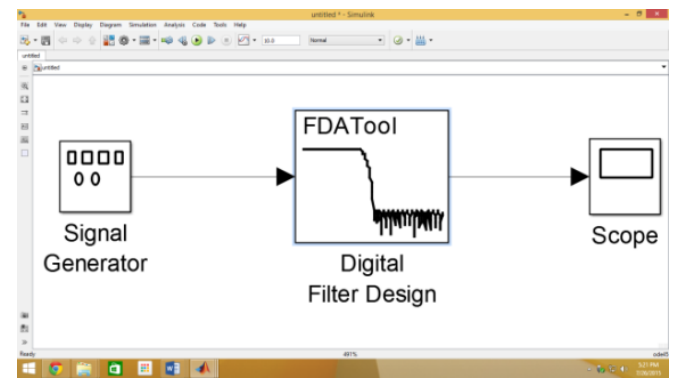

Gambar 1. Blok rangkaian simulasi filter IIR menggunakan Simulink

\subsection{Implementasi Filter IIR}

\subsubsection{Pemodelan Sistem}

Setelah simulasi selesai dilakukan, selanjutnya akan dilakukan proses implementasi ke DSK TMS320C6713 dengan bantuan software Code Composer Studio (CCS) untuk menunjukan hasil dari karakteristik filter yang dibutuhkan untuk merancang suatu filter digital IIR Elliptic dan 
Bessel pada LPF, HPF, BPF, dan BSF. Sebelum implementasi dibutuhkan pemodelan sistem yang nantinya akan di download ke DSK TMS320C6713, pemodelan sistem ini membutuhkan bantuan blok-blok DSK TMS320C6713 yang ada pada Simulink library dan nantinya dirangkai seperti pada Gambar 2.

\subsubsection{Implementasi Perancangan Filter pada DSK TMS320C6713}

Nilai koefisien filter yang diperoleh dari Simulink dengan matlab di-copy ke software CCS yang akan dikompilasi ulang dan hasilnya berupa kode hexa yang akan didownload ke DSK TMS320C6713. Dengan menghubungkan audio generator, DSK TMS320C6713, PC, dan oscilloscope dengan konektor yang sesuai. Menentukan daerah frekuensi kerja yang digunakan pada audio generator sehingga oscilloscope dapat menampilkan hasil output sinyal dari DSK TMS320C6713, hasilnya diamati dan dicatat. Hasil tersebut dibuat grafik respon frekeunsi berupa frekuensi terhadap magnitude. Langkah-langkah implementasi terdapat pada diagram alir Gambar 3.

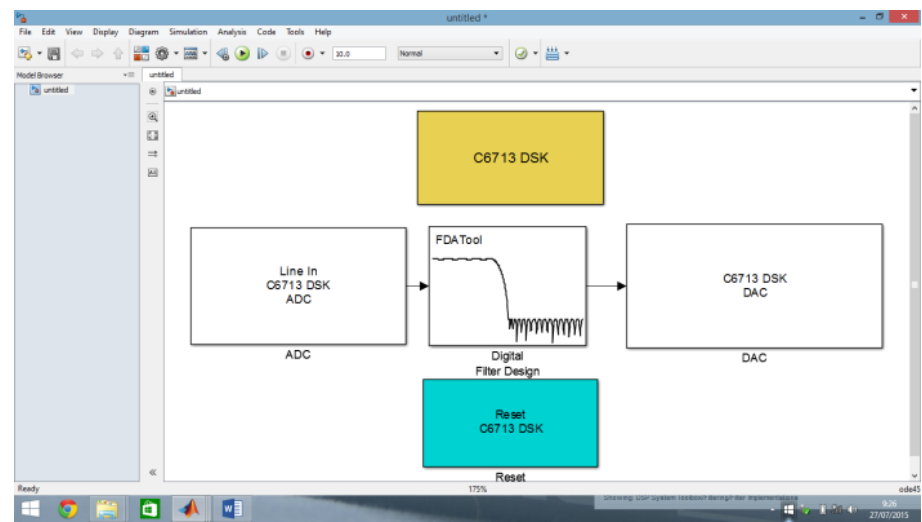

Gambar 2. Blok rangkaian implementasi filter IIR dengan MATLAB Simulink

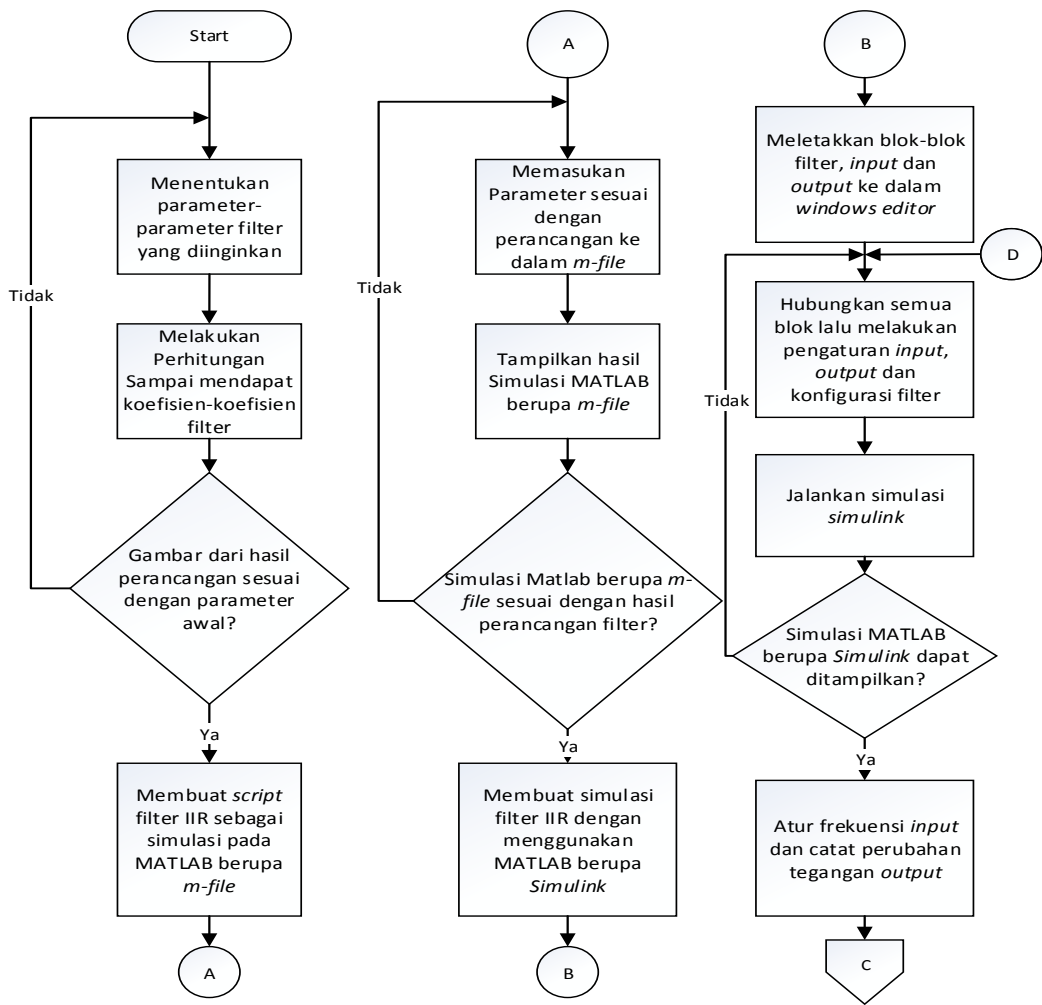

Gambar 3. Diagram Alir Implementasi Filter IIR 

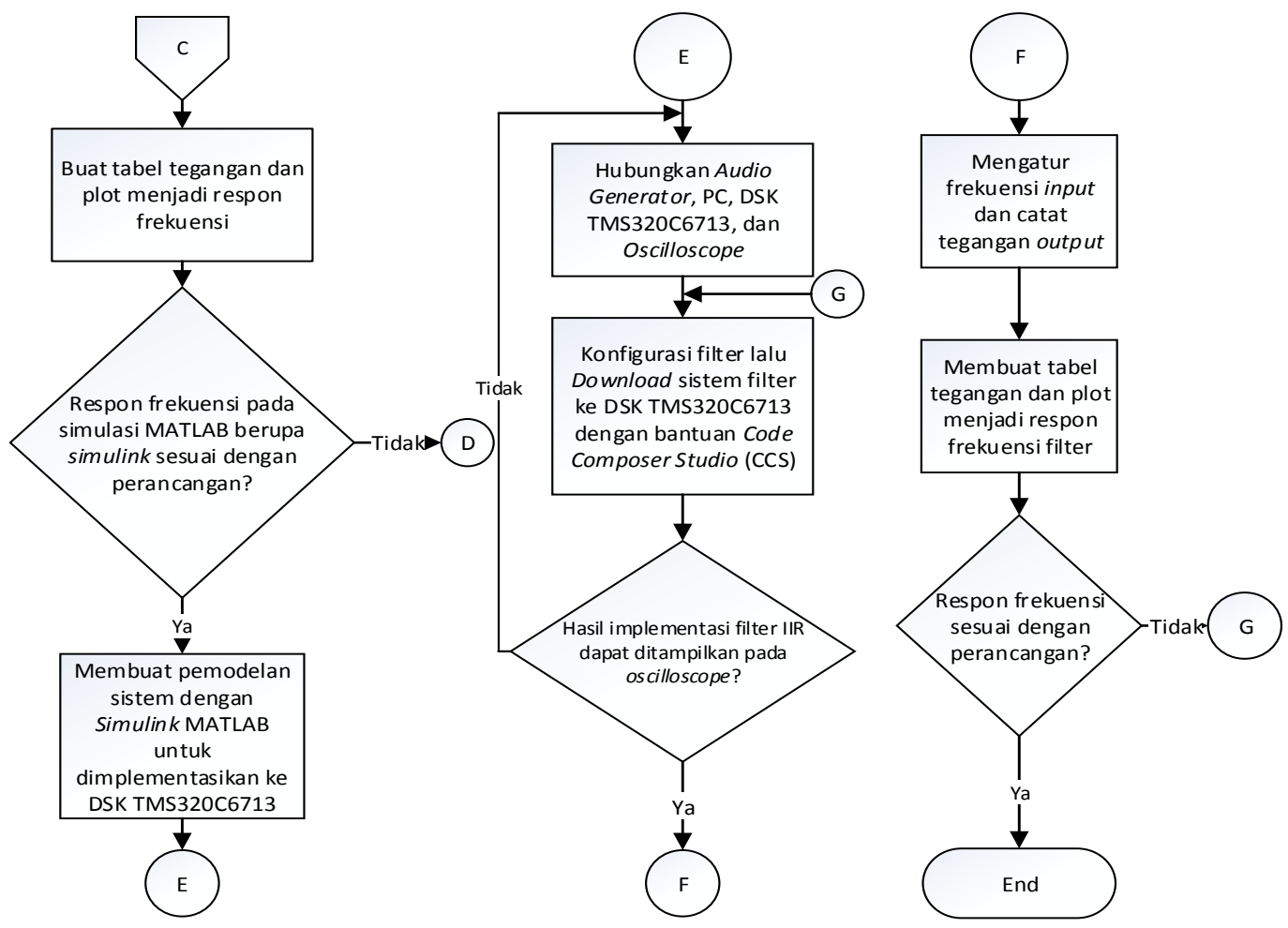

Gambar 4. Diagram Alir Implementasi Filter IIR (lanjutan)

\section{Pengujian dan Analisis}

Pada pengujian filter digital IIR dengan respon Elliptic dan Bessel dilakukan simulasi menggunakan Matlab terlebih dahulu, untuk melihat respon frekuensi yang dihasilkan oleh Low Pass Filter (LPF), High Pass Filter (HPF), Band Pass Filter (BPF), dan Band Stop Filter (BSF). Nilai-nilai dari spesifikasi filter seperti frekuensi cut-off, frekuensi passband, frekuensi stopband, ripple passband, ripple stopband dan redaman passband maupun stopband-nya yang ditentukan pada simulasi juga digunakan dengan besaran yang sama pada implementasinya. Pada implemantasi dengan DSK TMS3206713 dilihat juga respon frekuensi dari filter-filter seperti di simulasi. Dari pengujian akan dididapatkan data yang kemudian dianalisa untuk menentukan unjuk kerja filter hasil rancangan. Hasil dari simulasi dengan Matlab dan implementasi dengan DSK kemudian diuji dan dianalisis dan menghasilkan beberapa hal, seperti :

1. Grafik respon frekuensi Low Pass Filter (LPF), High Pass Filter (HPF), Band Pass Filter (BPF), dan Band Stop Filter (BSF) dari hasil simulasi filter yang menggunakan respon Elliptic dan Bessel.

2. Grafik respon frekuensi Low Pass Filter (LPF), High Pass Filter (HPF), Band Pass Filter (BPF), dan Band Stop Filter (BSF) dari hasil implementasi filter yang menggunakan respon Elliptic dan Bessel.

\subsection{Hasil Pengujian dan Analisis Simulasi pada MATLAB}

Pengujian dan Analisis pada Matlab akan meliputi 4 buah filter yaitu LPF, HPF, BPF, dan BSF dengan membandingkan dua respon frekuensi filter IIR, yaitu Elliptic dan Bessel. Menurut hasil yang didapat karakteristik kedua respon ini sangat berbeda namun dapat digunakan sesuai dengan kebutuhan alat yang akan direalisasikan. Elliptic memiliki roll-off yang tajam namun terdapat ripple di passband dan stopband. Bessel tidak terdapat ripple namun perpindahan antara 
passband dan stopband rata sehingga dibutuhkan frekuensi yang lebih lebar untuk mencapai stopband.

Untuk melihat karakteristik filter LPF, HPF, BPF, dan BSF pada filter IIR respon Elliptic dan Bessel dengan implementasi ke perangkat DSK TMS320C6713, digunakan audio generator sebagai sinyal input, dengan menghubungkan audio generator dengan DSK TMS320C6713 menggunakan kabel konektor ke channel Line In. Kemudian frekuensi pada audio generator diatur sebagai range frekuensi input ke DSK TMS320C6713. DSK TMS320C6713 dihubungkan dengan PC agar dapat men-download sistem yang telah dibuat. Sebagai hasil dari output filter dan alat ukut digunakan oscilloscope. Oscilloscope dihubungkan dengan DSK TMS320C6713 menggunakan konektor ke DSK TMS320C6713 menuju channel Line Out. Pada oscilloscope dapat melihat sinyal output (Vout) yang dihasilkan. Hasil yang dicatat berupa besarnya tegangan output (Vout) seiring dengan kenaikan frekuensi input. Besarnya tegangan input (Vin) yang digunakan sebesar $10 \mathrm{Vpp}$ dan frekuensi sampling $(\mathrm{Fs})=15000 \mathrm{~Hz}$.

Pada filter IIR respon frekuensi Bessel tidak dapat diimplementasikan ke DSK TMS320C6713 karena filter Bessel hanya dapat bekerja di filter analog. Terjadi error pada saat proses download ke DSK TMS320C6713, karena blok yang sudah ada yaitu Line in merupakan ADC (analog digital converter). Audio generator mengeluarkan sinyal analog lalu masuk ke Line in berubah menjadi sinyal digital, namun pada blok analog filter design input harus berupa sinyal analog sehingga terjadi error pada proses filternya.

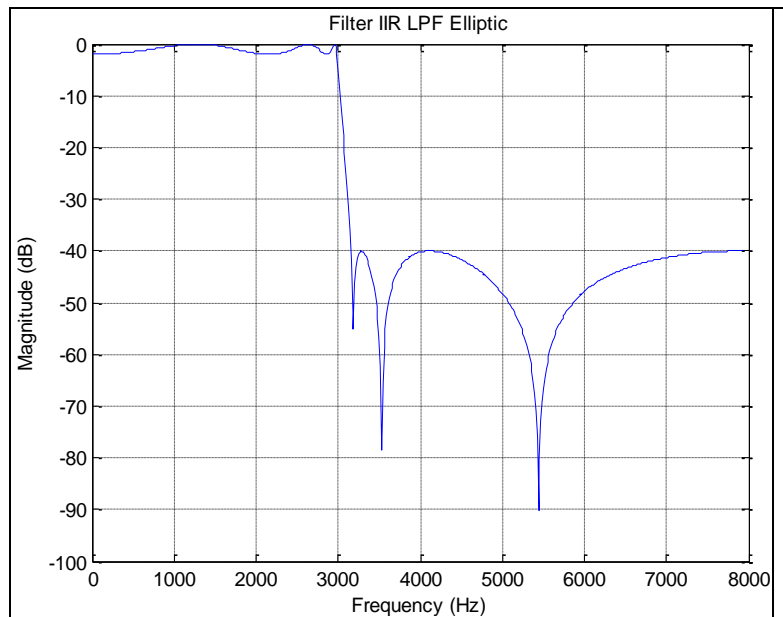

(a)

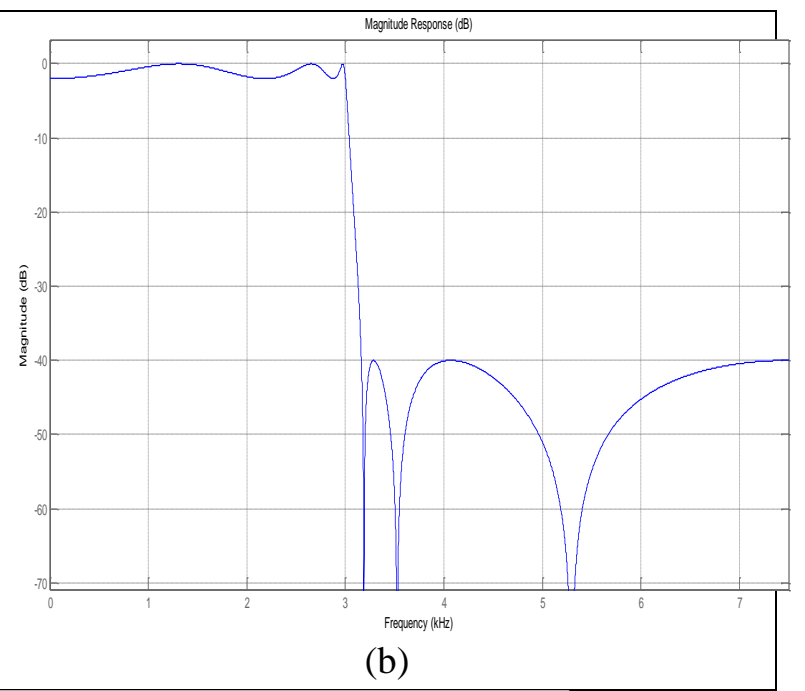

Filter IIR LPF Elliptic $N=6$

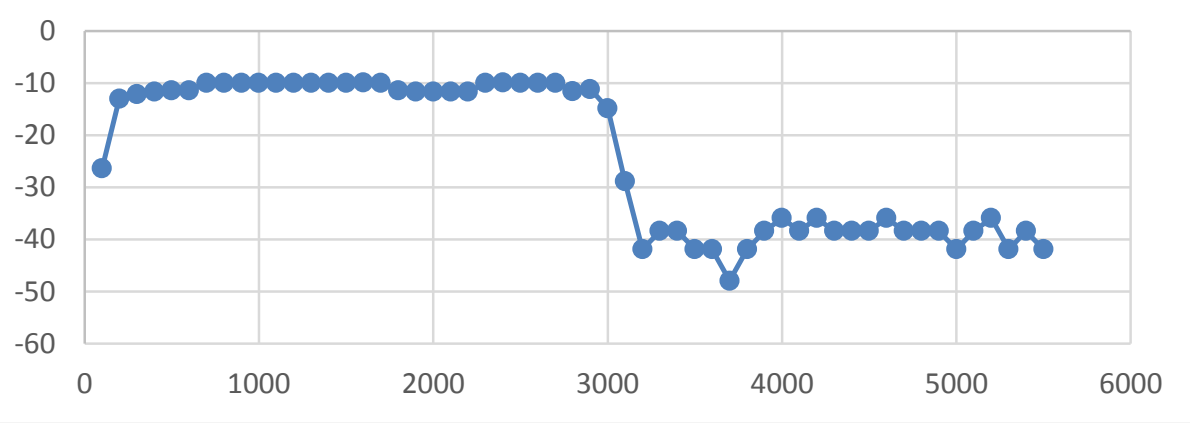

(c)

Gambar 5. Respon Magnitude simulasi dan Implementasi filter IIR LPF, (a) simulasi $m$-file (b) simulasi Simulink (c) Implementasi DSK TMS320C6713 
Pada hasil implementasi terjadi penurunan yang cukup besar tegangan output dari tegangan input, Hal ini dikarenakan terdapat redaman yang berdasal dari kabel dan konektor yang digunakan untuk menghubungkan perangkat yang digunakan (DSK TMS320C6713, audio generator, oscilloscope, PC). Hasil implementasi dapat dilihat pada Gambar 5. Pada grafik elliptic, sinyal turun dengan tajam pada saat $3000 \mathrm{~Hz}$ sampai $3500 \mathrm{~Hz}$ dan terdapat ripple pada passband dan stopband. Hasil dari simulasi MATLAB $m$-file atau simulink dan implementasi tidak berbeda sangat jauh namun perlu diperhatikan alat-alat yang dipakai pada saat implementasi karena alat-alat tersebut berpengaruh pada hasil yang akan didapat pada implementasi. Pada implementasi LPF ini berhasil melewatkan sinyal pada frekuensi passband dan stopband sesuai dengan perancangan dengan menggunakan orde yang didapat pada perhitungan. Memory used on the TMS320C6713 DSK of 2782 Bytes from the device owned $16 \mathrm{MB}$ sehingga memori yang digunakan tidak terlalu membebani DSK TMS320C6713.

Dari semua hasil simulasi dan implementasi, maka hasilnya dapat dirangkum seperti ditunjukan oleh tabel 1:

Tabel 1. Parameter Filter Hasil Simulasi

\begin{tabular}{|c|c|c|c|c|c|c|c|c|c|c|}
\hline \multirow{3}{*}{ Tipe Filter } & \multicolumn{4}{|c|}{ Frekuensi cut-off } & \multirow{2}{*}{\multicolumn{2}{|c|}{$\begin{array}{c}\text { Stopband } \\
\text { Attenuation } \\
\text { (dB) }\end{array}$}} & \multirow{2}{*}{\multicolumn{2}{|c|}{ Bandwidth }} & \multirow{2}{*}{\multicolumn{2}{|c|}{$\begin{array}{c}\text { Faktor } \\
\text { kualitas }\end{array}$}} \\
\hline & \multicolumn{2}{|c|}{ Simulasi } & \multicolumn{2}{|c|}{$\begin{array}{c}\text { Implementa } \\
\text { si }\end{array}$} & & & & & & \\
\hline & $\begin{array}{l}\text { Fc1 } \\
(\mathbf{H z})\end{array}$ & $\begin{array}{l}\text { Fc2 } \\
(\mathrm{Hz})\end{array}$ & $\begin{array}{l}\text { Fc1 } \\
(\mathbf{H z})\end{array}$ & $\begin{array}{l}\text { Fc2 } \\
(\mathrm{Hz})\end{array}$ & $\begin{array}{c}\text { Simu } \\
\text { lasi }\end{array}$ & $\begin{array}{c}\text { Impl } \\
\text { eme } \\
\text { ntasi }\end{array}$ & $\begin{array}{c}\text { Simu } \\
\text { lasi }\end{array}$ & $\begin{array}{c}\text { Impl } \\
\text { eme } \\
\text { ntasi }\end{array}$ & $\begin{array}{c}\text { Simu } \\
\text { lasi }\end{array}$ & $\begin{array}{c}\text { Imple } \\
\text { menta } \\
\text { si }\end{array}$ \\
\hline LPF Elliptic & 3250 & - & 3000 & - & -40 & -42 & - & - & - & - \\
\hline HPF Elliptic & 3250 & - & 3500 & - & -40 & -36 & - & - & - & - \\
\hline BPF Elliptic & 2750 & 5250 & 3500 & 5000 & -40 & -36 & 2500 & 1500 & 1,6 & 2,83 \\
\hline BSF Elliptic & 2750 & 5250 & 3000 & 5500 & -40 & -13 & 2500 & 1500 & 1, & 2,83 \\
\hline LPF Bessel & 1000 & - & - & - & - & - & - & - & - & \\
\hline HPF Bessel & 5000 & - & - & - & - & - & - & - & - & \\
\hline BSF Bessel & 2100 & 3500 & - & - & - & - & 1400 & - & 2 & - \\
\hline BPF Bessel & 1900 & 5000 & - & - & - & - & 3100 & - & 1,12 & - \\
\hline
\end{tabular}

Hasil dari simulasi dan implementasi ditunjukkan pada tabel 1 dapat dibandingkan parameter filter berupa pengujian frekuensi cut-off yang bertujuan untuk mengetahui ketepatan frekuensi cut-off hasil simulasi dengan hasil implementasi yang hasilnya tidak ada penyimpangan yang cukup signifikan. Pada pengujian redaman stopband attenuation atau nilai gain tertinggi yang terjadi di daerah stopband yang bertujuan untuk mengetahui besarnya redaman yang dihasilkan filter. Secara teoritis semakin kecil atau semakin negative nilai redaman maka filter semakin baik, hal ini dikarenakan frekuensi yang tidak diinginkan dapat benar-benar dilemahkan, pada hasil percobaan simulasi lebih baik dibanding hasil implementasi. Sementara dari faktor kualitas untuk filter BPF dan BSF Elliptic hasil simulasi dan implementasi tidak terjadi penyimpangan yang jauh. 


\section{KESIMPULAN DAN SARAN}

\subsection{KESIMPULAN}

Setelah melakukan pengujian dan analisis dari simulasi dan implementasi filter IIR dengan

Respon frekuensi Elliptic dan Bessel, maka diperoleh kesimpulan sebagai berikut:

1. Perbedaan stopband attenuation pada hasil simulasi didapat $-40 \mathrm{~dB}$ untuk semua filter dan implementasi didapat $-42 \mathrm{~dB},-36 \mathrm{~dB},-36 \mathrm{~dB}$, dan $-13 \mathrm{~dB}$. Hal ini dapat disebabkan oleh alat-alat yang digunakan pada implementasi

2. Untuk perancangan filter simulasi dan implementasi filter dengan respon Elliptic dan Bessel menggunakan frekuensi passband yang sama dan menggunakan orde filter yang sama yaitu 6. Penurunan dan kenaikan dari yang dihasilkan oleh filter Elliptic sangat tajam menuju ke daerah stopband yaitu 3000-3500 Hz namun terdapat ripple pada passband dan stopband. Sedangkan penurunan dan kan yang dihasilkan filter Bessel cenderung rata yaitu 3000-5000 $\mathrm{Hz}$ namun pada frekuensi sudah mulai sedikit sehingga daerah stopband-nya berbeda jauh dengan filter Elliptic namun filter Bessel tidak terdapat ripple.

3. Respon Magnitude LPF, HPF, BPF, dan BSF yang dihasilkan dari implementasi dengan DSK TMS320C6713 tidak berbeda jauh dengan hasil simulasi yang dihasilkan Matlab, tetapi cukup berbeda pada frekuensi dan ripple-nya.

4. Pada tegangan input yang didapat $10 \mathrm{~V}$ dan output didapat sekitar $3 \mathrm{~V}$, terdapat perbedaan hal ini disebabkan karena terdapat pada redaman yang terdapat pada kabel dan konektor yang digunakan Bandwith pada Elliptic yang didapat pada simulasi yaitu $2500 \mathrm{~Hz}$ dan pada implementasi yaitu $1500 \mathrm{~Hz}$, pada simulasi bisa mendapatkan lebih besar karena simulasi MATLAB mengacu pada teori sehingga hasil yang muncul mendekati ideal.

\subsection{Saran}

1. Perlunya dilakukan perbandingan keempat filter IIR untuk dapat melihat filter yang dapat digunakan sesuai dengan kebutuhan perangkat yang akan direaliasikan.

2. Pada pengujian perlu dilakukan dengan lebih akurat lagi dengan perhitungan kabel dan konektor yang digunakan.

3. Pengujian juga dapat dilakukan dengan menggunakan audio sehingga hasil yang didapatkan dapat lebih bervariasi.

4. Diharapkan simulasi dan impementasi filter IIR ini bisa dibuat dengan analog filter nya sehingga dapat melihat perbedaannya dengan implementasi menggunakan Digital Signal Processor (DSP) dengan DSK TMS320C6713 atau kit DSP lainnya.

\section{Daftar Pustaka:}

[1] Aswan, Muhammad. 2010. Pewujudan Tapis Digital Bandpass IIR Menggunakan DSK TMS320C6713TMTM Berbasis Simulink. Universitas Dipenogoro, Semarang.

[2] Gidion, Erwin. 2011. Pewujudan Tapisdigitalfir Pemilih Frekuensi Menggunakan DSK TMS320C6713. Universitas Dipenogoro, Semarang.

[3] Ludeman, Lonnie C. 1987. Fundamentals of Digital Signal Processing. New Mexico State University

[4] Proakis, John G., \& Manokalis, Dimitris. 1996. Digital Signal Processing Principles, Algorithms, and Applications. United States of America: Northeastern University.

[5] Suparman, Solihin. 2013. Simulasi Perancangan Filter Analog dengan Respon Chebyshev menggunakan Matlab versi 7.9. Institut Teknologi Nasional, Bandung.

[6] Tamba, Alfin. 2015. Implementasi Filter Infinte Impulse Response (IIR) dengan Respon Butterworth dan Chebyshev Menggunakan DSK TMS320C6713. Institut Teknologi Nasional, Bandung.

[7] Tim asisten Laboratorium Telekomunikasi. 2012. Modul Praktikum Pengolahan Sinyal Diskrit. Institut Teknologi Nasional, Bandung. 